\title{
Genotype-by-environment interaction for seed glucosinolate content in winter oilseed rape (Brassica napus L.) using an additive main effects and multiplicative interaction model
}

\author{
Jan Bocianowski ${ }^{1}$, Kamila Nowosad ${ }^{2}$, Alina Liersch ${ }^{3}$, Wiesława Popławska ${ }^{3}$, \\ Agnieszka Lącka ${ }^{2}$ \\ ${ }^{1}$ Poznań University of Life Sciences, Department of Mathematical and Statistical Methods, Wojska \\ Polskiego 28, 60-637 Poznań, Poland, e-mail: jan.bocianowski@up.poznan.pl \\ ${ }^{2}$ Wroclaw University of Environmental and Life Sciences, Department of Genetics, Plant Breeding \\ and Seed Production, Grunwaldzki 24A, 53-363 Wrocław, Poland, \\ e-mails: kamila.nowosad@upwr.edu.pl, agnieszka.lacka@upwr.edu.pl \\ ${ }^{3}$ Plant Breeding and Acclimatization Institute - National Research Institute, Department \\ of Oilseed Crops, Strzeszyńska 36, 60-479 Poznań, Poland, \\ e-mails: alal@nico.ihar.poznan.pl,wiesp@nico.ihar.poznan.pl
}

\begin{abstract}
SUMMARY
The objective of this study was to assess genotype-by-environment interaction for seed glucosinolate content in winter rapeseed cultivars grown in western Poland using the additive main effects and multiplicative interaction model. The study concerned 25 winter rapeseed genotypes ( $15 \mathrm{~F}_{1} \mathrm{CMS}$ ogura hybrids, parental lines and two European cultivars: open pollinated Californium and $\mathrm{F}_{1}$ hybrid Hercules), evaluated at five locations in a randomized complete block design with four replicates. The seed glucosinolate content of the tested genotypes ranged from 5.53 to $16.80 \mu \mathrm{mol} \cdot \mathrm{g}^{-1}$ of seeds, with an average of $10.26 \mu \mathrm{mol} \cdot \mathrm{g}^{-1}$. In the AMMI analyses, $48.67 \%$ of the seed glucosinolate content variation was explained by environment, $13.07 \%$ by differences between genotypes, and $17.56 \%$ by genotype-by-environment interaction. The hybrid PN66×PN07 is recommended for further inclusion in the breeding program due to its low average seed glucosinolate content; the restorer line PN18, CMS ogura line PN66 and hybrids PN66 $\times$ PN18 and PN66 $\times$ PN21 are recommended because of their stability and low seed glucosinolate content.
\end{abstract}

Key words: Brassica napus; seed glucosinolate content; AMMI; stability. 


\section{Introduction}

Oilseed rape (Brassica napus ssp. napus; genome AACC, $2 \mathrm{n}=38$ ) is one of the major global oil crops and the most important source of vegetable oil in Europe. Its oil is used as a green fuel, for human consumption, for feeding animals, and in the chemical and pharmaceutical industries (Friedt and Snowdon 2009). All oilseed rape production in Europe is from types with zero erucic acid (up to $2 \%$ in consumption seeds) and low seed glucosinolate content (up to $25 \mu \mathrm{mol} \cdot \mathrm{g}^{-1}$ of seeds) - called canola quality or double low " 00 " quality oilseed rape. The oil content in mature seeds ranges from $45 \%$ to $50 \%$, and the protein content ranges from $21 \%$ to $24 \%$.

Rapeseed oil from 00-quality cultivars is classified as one of the healthiest vegetable oils due to its fatty acid composition (Szydłowska-Czerniak et al. 2011). Besides the high-quality oil, the residual meal from the seeds of oilseed rape after oil extraction also provides a protein-rich (38-44\%) animal feed. This meal represents a favorable composition of amino acids, including comparatively high contents of the essential sulfuric amino acids methionine and cysteine (Downey and Bell 1990). In addition, the meal is rich in minerals (particularly $\mathrm{Ca}$, Mg and P) and contains vitamins B4 and E (Thies 1994). However, the presence of glucosinolates (mainly alkenyl), their degradation products and other antinutritive compounds limits the use of rich-protein meal as a feed supplement for livestock (beef) and particularly for monogastric animals (Walker and Booth 2001). On the other hand, glucosinolates (especially indolyl) and their degradation products play an important role in pest and disease defense reactions (Rask et al. 2000; Zhao and Meng 2003). When plant tissue is damaged the glucosinolates are hydrolyzed by the myrosinases to release a range of defense compounds from substrate cells (Mithen et al. 2000).

Breeding programs of rapeseed cultivars are carried out with the aim of reducing or totally eliminating alkenyl glucosinolates while simultaneously reducing anti-nutritional components of Brassica seeds, such as sinapine and the related phenolic acid, tannins, and phytic acid (Zhao and Meng 2003; Friedt and 
Snowdon 2009; Wittkop et al. 2009). The composition and contents of glucosinolates are influenced by the genotype, climate and cultivation conditions, including fertilization, harvest time and plant position. Bocianowski et al. (2009), Friedt and Snowdon (2009) and Liersch et al. (2013) report that the gross seed composition can vary widely depending on both genetic and environmental factors, with a large influence of temperature, water and nutrient supply. Bocianowski et al. (2011) showed that the main effects of environment were significant for total alkenyl glucosinolates in a study of 18 parental lines of winter oilseed rape $\mathrm{F}_{1}$ CMS ogura hybrids.

Better knowledge of the genetic determinism of seed glucosinolate content may help breeders to control the genetic advance for the crop (Uzunova et al. 1995; Howell et al. 2003). Seed glucosinolate content is a very complex quantitative trait, the expression of which is the result of genotype, environmental conditions (e.g. temperature, water and nutrient supply) and genotype $\times$ environment (GE) interaction (Popławska et al. 2007). The importance of GE interactions in plant breeding programs have been a focus of attention for breeders (Popławska et al. 2001; Chen et al. 2017). The GE interaction may be analyzed using the additive main effects and multiplicative interaction (AMMI) model (Zobel et al. 1988). The AMMI model combines ANOVA for the genotype and environment main effects and principal component analysis (PCA) with multiplicative parameters.

The objective of this paper was to assess GE interaction for seed glucosinolate content (GLC) in winter oilseed rape using the AMMI model.

\section{Material and Methods}

The plant material for field trials consisted of 25 winter rapeseed genotypes: $15 \mathrm{~F}_{1}$ CMS ogura hybrids $(\mathrm{PN} 64 \times \mathrm{PN} 17, \mathrm{PN} 64 \times \mathrm{PN} 18, \mathrm{PN} 64 \times \mathrm{PN} 21, \mathrm{PN} 64 \times \mathrm{PN} 05$, PN64 $\times$ PN07, PN66 $\times$ PN17, PN66 $\times$ PN18, PN66 $\times$ PN21, PN66 $\times$ PN05, PN66 $\times$ PN07, $\quad$ PN68 $\times$ PN17, $\quad$ PN68 $\times$ PN18, $\quad$ PN6 $8 \times$ PN21, $\quad$ PN68 $\times$ PN05, PN68 $\times$ PN07), five restorer lines for the Ogura system (PN05, PN07, PN17, 
PN18, PN21), three CMS ogura lines (PN64, PN66, PN68) and two European cultivars (Californium and Hercules $\mathrm{F}_{1}$ ). The study was carried out at five

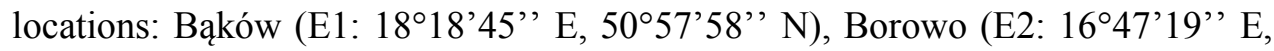

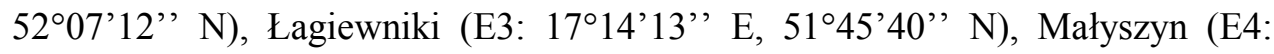

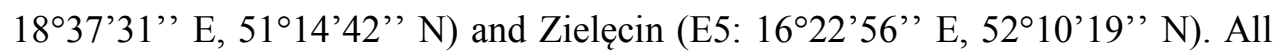
field trials used randomized complete block designs with four replicates (Nowosad et al. 2016). After harvesting, seeds from each replicate plot were analyzed. Analysis of seed GLC (in $\mu \mathrm{mol} \mathrm{\textrm {g } ^ { - 1 }}$ seeds) was performed via gas chromatography of the silyl derivatives of desulfoglucosinolates (PN ISO 91671:1999, 1999). Two-way ANOVA was performed to verify the hypothesis of a lack of effects of genotype, environment and their interaction on seed GLC. Least-squares means were simultaneously produced for the AMMI model. The model first fits additive effects for the main effects of genotype $(G)$ and environment (E) followed by multiplicative effects for GE interaction using PCA. The AMMI model (Gauch and Zobel 1990; Nowosad et al. 2017) is given by:

$$
y_{g e}=\mu+\alpha_{g}+\beta_{e}+\sum_{n=1}^{N} \lambda_{n} \gamma_{g n} \delta_{e n}+Q_{g e},
$$

where $y_{g e}$ is the mean seed GLC of genotype $g$ in environment $e, \mu$ is the grand mean, $\alpha_{g}$ is the genotypic mean deviation, $\beta_{e}$ is the environmental mean deviation, $N$ is the number of PCA axes retained in the adjusted model, $\lambda_{n}$ is the square root of the eigenvalue of PCA axis $n, \gamma_{g n}$ is the genotype score for PCA axis $n, \delta_{e n}$ is the score eigenvector for PCA axis $n$, and $Q_{g e}$ is the residual. The expected distribution of $Q_{g e}$ is normal. The AMMI stability value (ASV) was used to compare the stability of genotypes as described by Purchase et al. (2000):

$$
A S V=\sqrt{\left.\frac{S S_{I P C A 1}}{S S_{I P C A 2}}\left(I P C A_{1}\right)\right]^{2}+\left(I P C A_{2}\right)^{2}},
$$

where $S S$ is the sum of squares, IPCA1 and IPCA2 are the first and second interaction principal component axes, and $\mathrm{IPCA}_{1}$ and $\mathrm{IPCA}_{2}$ are the genotypic scores in the AMMI model. ASV is the distance from zero in a two-dimensional 
scatterplot of IPCA 1 scores against IPCA 2 scores. Since the $\mathrm{IPCA}_{1}$ score contributes more to the GE sum of squares, it has to be weighted by the proportional difference between IPCA $A_{1}$ and IPCA $_{2}$ scores to compensate for the difference in contribution. The distance from zero is then determined using Pythagoras's theorem. The greater the IPCA score, either negative or positive, the more specifically adapted the genotype is to certain environments. A smaller ASV score indicates a more stable genotype across environments. The level of significance in PCA analysis was tested with the $F$ test. For the AMMI analysis, the statistical package GenStat v. 18.2 was used.

\section{Results and Discussion}

The three sources of variation were highly significant. The sum of squares for environment main effects represented $48.67 \%$ of the total seed GLC variation (Table 1). The differences between genotypes explained $13.07 \%$ of the seed GLC variation, and the effects of GE interaction $17.56 \%$. The two principal components of GE interaction accounted jointly for $86.39 \%$ of the whole of its effect on the variation of seed GLC, and were highly significant. The first principal component (IPCA 1) accounted for $66.28 \%$ of the variation caused by interaction, while IPCA 2 accounted for $20.10 \%$. Seed GLC of the tested genotypes varied from 5.53 (for PN18 in E3) to $16.80 \mu \mathrm{mol} \cdot \mathrm{g}^{-1}$ of seeds (for PN66 $\times$ PN07 in E4) throughout the five seasons, with an average of $10.26 \mu \mathrm{mol} \cdot \mathrm{g}$

1 (Table 2). The PN68 $\times$ PN07 hybrid had the highest average seed GLC, and the line PN66 $\times$ PN07 had the lowest $\left(8.74 \mu \mathrm{mol} \cdot \mathrm{g}^{-1}\right)$. The average seed GLC per location varied from $7.04 \mu \mathrm{mol} \cdot \mathrm{g}^{-1}$ in Lagiewniki, to $13.35 \mu \mathrm{mol} \cdot \mathrm{g}^{-1}$ in Borowo.

Seed GLC in winter oilseed rape (Brassica napus L.) is a trait determined by multiple genes that cause change in the performance of genotypes depending on the cultivation environment. Brown et al. (2002), Farnham et al. (2004) and Iniguez-Luy and Federico (2011) report large GE interaction for glucosinolate content. 
Table 1. Analysis of variance of main effects and interactions for rapeseed (Brassica napus L.) lines' seed glucosinolate content

\begin{tabular}{llllll}
\hline $\begin{array}{l}\text { Source of } \\
\text { variation }\end{array}$ & d.f. & $\begin{array}{l}\text { Sum of } \\
\text { squares }\end{array}$ & $\begin{array}{l}\text { Mean } \\
\text { squares }\end{array}$ & $F$-statistic & $\begin{array}{l}\text { Variability } \\
\text { explained (\%) }\end{array}$ \\
\hline Treatments & 124 & 3481 & 28.07 & $9.34^{* * *}$ & 79.28 \\
Genotypes & 24 & 574 & 23.91 & $7.95 * * *$ & 13.07 \\
Environments & 4 & 2137 & 534.21 & $50.8^{* * *}$ & 48.67 \\
GE Interactions & 96 & 771 & 8.03 & $2.67 * * *$ & 17.56 \\
IPCA 1 & 27 & 511 & 18.91 & $6.29 * * *$ & 66.28 \\
IPCA 2 & 25 & 155 & 6.18 & $2.06^{* *}$ & 20.10 \\
Error & 264 & 794 & 3.01 & & \\
\hline$* * \mathrm{P}<0.01 ; * * *$ & $\mathrm{P}<0.001 ;$ IPCA: principal component of interaction
\end{tabular}

The AMMI1 biplot (Figure 1) shows the stability of genotypes and environments, as well as specific GE interactions. Among the tested genotypes, IPCA 1 values ranged from -1.769 (PN68×PN07) to $1.262(\mathrm{PN} 66 \times \mathrm{PN} 21)$, while among tested environments they ranged from -1.880 (Małyszyn) to 2.667 (Borowo) (Figure 1). The stability of a genotype is considered to mean consistent reaction to changing environmental conditions, biotic and abiotic stresses, agronomic factors and weather conditions. Figure 2 presents the biplot for seed GLC. The hybrid PN68 $\times$ PN07, cultivar Hercules $F_{1}$ and line G01 interacted positively with the locations E1 and E4, but negatively with E2 and E3 (Figures 1 and 2). The hybrids PN64 $\times \mathrm{PN} 18, \mathrm{PN} 64 \times \mathrm{PN} 21$ and $\mathrm{PN} 68 \times \mathrm{PN} 17$ interacted positively with the location E2, but negatively with E1, E3, E4 and E5. Some genotypes have high adaptation; however, most of them have specific adaptability. AMMI stability values (ASV) revealed variations in seed GLC stability among the 25 genotypes (Table 2). According to Purchase et al. (2000), a stable variety is defined as one with an ASV value close to zero. Consequently, the line PN18, with an ASV of 0.26, and the hybrid PN64×PN21, with an ASV of 0.33, were the most stable, while hybrids such as PN68×PN07 (5.48) and PN66 $\times$ PN21 (4.17) were the least stable (Table 2). The hybrid PN68 $\times$ PN18, with average seed GLC close to the overall mean of $10.26 \mu \mathrm{mol} \cdot \mathrm{g}^{-1}$ of seeds, is distinguished on the biplot. This hybrid had the highest stability. The hybrids PN66 $\times$ PN18 and PN66 $\times$ PN21 and the line PN18 had the lowest average values of seed GLC, and low AMMI stability values (Figure 2, Table 2). 


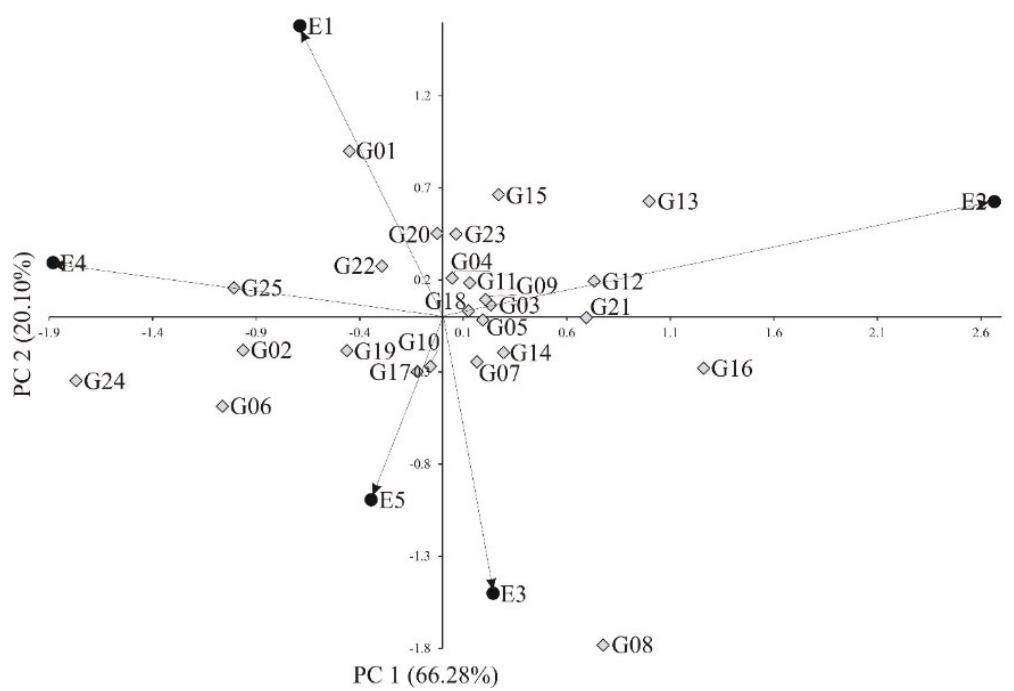

Figure 1. Biplot for genotype-by-environment interaction of seed glucosinolate content in winter rapeseed (Brassica napus L.) lines and hybrids in five environments, showing the effects of primary and secondary components (IPCA 1 and IPCA 2 respectively)

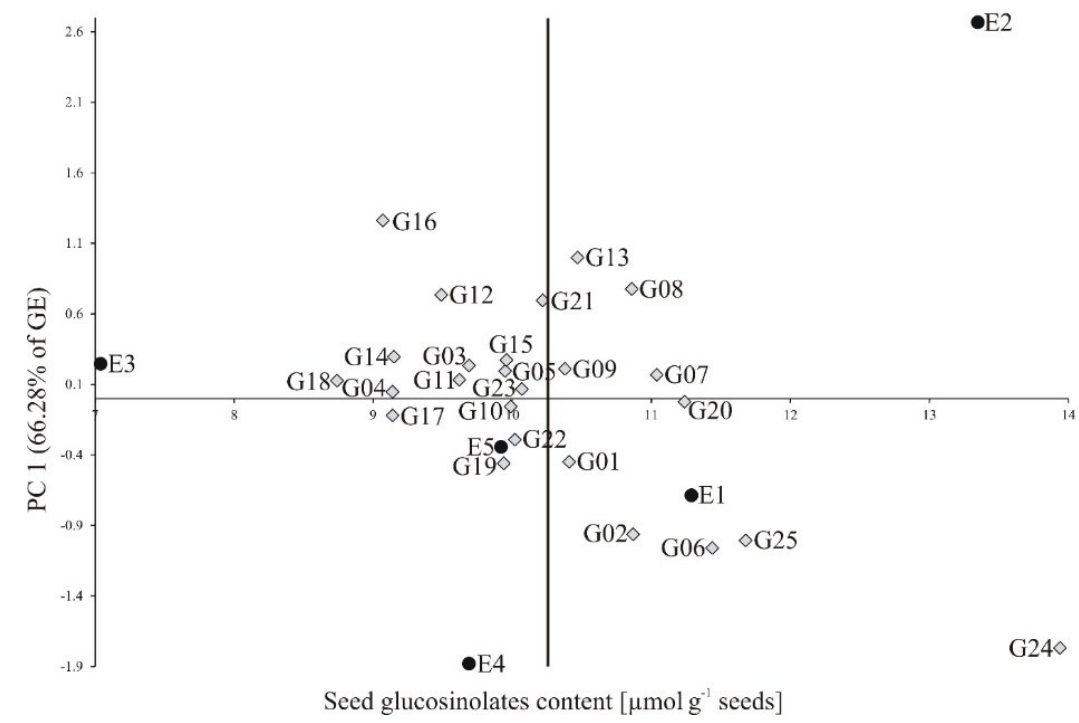

Figure 2. Biplot for the primary component of interaction (IPCA 1) and average rapeseed (Brassica napus L.) seed glucosinolate content ( $\mu \mathrm{mol} \cdot \mathrm{g}^{-1}$ of seeds). The vertical line at the center of the biplot is the overall grand mean 
Table 2. Average seed glucosinolate content ( $\mu \mathrm{mol} \cdot \mathrm{g}^{-1}$ of seeds), for genotypes and environments, principal component analysis values of tested rapeseed (Brassica napus L.) lines and hybrids, and AMMI stability value (ASV)

\begin{tabular}{|c|c|c|c|c|c|c|c|c|c|c|}
\hline Genotype & Code & E1 & E2 & E3 & E4 & E5 & Mean & IPCA 1 & IPCA 2 & ASV \\
\hline Californium & G01 & 13.25 & 12.82 & 6.23 & 11.05 & 8.73 & 10.41 & -0.449 & 0.899 & 1.73 \\
\hline Hercules $\mathrm{F}_{1}$ & G02 & 12.05 & 11.40 & 7.68 & 12.35 & 10.88 & 10.87 & -0.963 & -0.182 & 3.18 \\
\hline PN17 & G03 & 10.85 & 13.33 & 5.80 & 8.20 & 10.25 & 9.69 & 0.233 & 0.064 & 0.77 \\
\hline PN18 & G04 & 10.20 & 12.62 & 5.53 & 8.85 & 8.47 & 9.14 & 0.047 & 0.209 & 0.26 \\
\hline PN21 & G05 & 10.25 & 13.85 & 5.93 & 9.40 & 10.30 & 9.95 & 0.195 & -0.017 & 0.64 \\
\hline PN05 & G06 & 12.25 & 11.50 & 8.50 & 12.90 & 12.08 & 11.44 & -1.062 & -0.487 & 3.53 \\
\hline PN64 & G07 & 11.75 & 14.32 & 7.95 & 9.75 & 11.45 & 11.04 & 0.167 & -0.246 & 0.60 \\
\hline PN64×PN17 & G08 & 8.45 & 14.95 & 10.97 & 8.60 & 11.30 & 10.86 & 0.777 & -1.783 & 3.12 \\
\hline PN64×PN18 & G09 & 10.70 & 14.47 & 6.75 & 10.25 & 9.72 & 10.38 & 0.209 & 0.092 & 0.70 \\
\hline PN64×PN21 & G10 & 10.55 & 12.80 & 7.12 & 9.55 & 9.93 & 9.99 & -0.059 & -0.270 & 0.33 \\
\hline PN64×PN05 & G11 & 10.70 & 13.25 & 6.30 & 9.10 & 8.72 & 9.62 & 0.132 & 0.184 & 0.47 \\
\hline PN64×PN07 & G12 & 10.45 & 14.58 & 6.10 & 7.40 & 8.90 & 9.49 & 0.733 & 0.193 & 2.42 \\
\hline PN66 & G13 & 11.80 & 16.62 & 6.88 & 8.35 & 8.72 & 10.47 & 0.999 & 0.628 & 3.35 \\
\hline PN66×PN17 & G14 & 9.95 & 12.75 & 6.67 & 7.75 & 8.62 & 9.15 & 0.295 & -0.195 & 0.99 \\
\hline PN66×PN18 & G15 & 12.75 & 13.70 & 6.55 & 8.20 & 8.62 & 9.96 & 0.272 & 0.663 & 1.11 \\
\hline PN66×PN21 & G16 & 8.55 & 15.47 & 6.70 & 6.40 & 8.20 & 9.07 & 1.262 & -0.279 & 4.17 \\
\hline PN66×PN05 & G17 & 11.30 & 10.88 & 6.92 & 6.95 & 9.63 & 9.14 & -0.121 & -0.299 & 0.50 \\
\hline PN66×PN07 & G18 & 9.75 & 12.17 & 5.83 & 8.05 & 7.90 & 8.74 & 0.126 & 0.032 & 0.42 \\
\hline PN68 & G19 & 11.10 & 11.62 & 6.50 & 9.90 & 10.57 & 9.94 & -0.461 & -0.184 & 1.53 \\
\hline PN68×PN17 & G20 & 12.55 & 14.80 & 7.07 & 11.35 & 10.45 & 11.24 & -0.025 & 0.452 & 0.46 \\
\hline PN68×PN18 & G21 & 10.90 & 15.08 & 6.65 & 7.95 & 10.50 & 10.22 & 0.695 & -0.005 & 2.29 \\
\hline PN68×PN21 & G22 & 10.55 & 13.12 & 6.15 & 11.50 & 8.77 & 10.02 & -0.292 & 0.274 & 1.00 \\
\hline PN68×PN05 & G23 & 11.85 & 13.58 & 6.17 & 9.40 & 9.38 & 10.07 & 0.066 & 0.449 & 0.50 \\
\hline PN68×PN07 & $\mathrm{G} 24$ & 15.55 & 12.15 & 11.00 & 16.80 & 14.22 & 13.94 & -1.769 & -0.348 & 5.84 \\
\hline PN07 & $\mathrm{G} 25$ & 14.25 & 11.85 & 8.18 & 12.35 & 11.78 & 11.68 & -1.007 & 0.157 & 3.32 \\
\hline Mean & & 11.29 & 13.35 & 7.04 & 9.69 & 9.92 & 10.26 & & & \\
\hline IPCA 1 & & -0.688 & 2.667 & 0.246 & -1.880 & -0.344 & & & & \\
\hline IPCA 2 & & 1.579 & 0.624 & -1.503 & 0.293 & -0.994 & & & & \\
\hline
\end{tabular}


The use in breeding of parental lines (restorer lines and CMS ogura lines) with very low GLC makes it possible to obtain restored hybrid seeds with GLC matching the Polish standard for sowing material: up to $18 \mu \mathrm{mol} \cdot \mathrm{g}^{-1}$ of seeds. Environmental conditions have a significant influence on GLC. The availability of sulfur in the soil and humidity conditions have been found to determine GLC in seeds of winter oilseed rape (Mailer and Cornish 1987; Clossais-Besnard 1991; Wielebski 2006). In low precipitation conditions the content of glucosinolates increases significantly (Mailer and Cornish 1987; Bouchereau et al. 1996). Jensen et al. (1996) showed that the size of rainfall deficiency is more significant than the duration of a drought. They also point to the relationship between soil texture and GLC, and state that the content of glucosinolates is lower on heavier soils. This is consistent with the results obtained in this study. The seeds of rapeseed collected in Lagiewniki (E3 - sandy clay loam) had the lowest seed GLC compared with the seeds collected in Zielęcin (E5), Małyszyn (E4) and Borowo (E2) (light textured soil - loamy sand). In the conditions of light textured soils as found in Borowo, Małyszyn and Zielęcin, the GLC depended on genotype (inheritance of GLC) and weather conditions, especially rainfall in the spring season (Nowosad et al. 2016).

The AMMI biplot allows the visualization of the main effects of the genotypes in different environments, in addition to the most important GE interactions. The AMMI model provides a useful tool in diagnosing GE interaction patterns and improving the accuracy of response estimates. It enables clustering of genotypes based on similarity of response characteristics and identification of potential trends across environments. The suggested strategy could extract more information from the GE interaction, thereby aiding researchers in identifying specific cultivars with competitive yields across diverse environments. The genotype and environment main effects as well as GE interaction had the strongest effect on seed GLC expression in western Poland. AMMI analyses revealed significant GE interaction with respect to seed GLC. AMMI models are capable of measuring the importance of environments, 
genotypes and their interactions through a value that measures how stable a genotype is in all environments in terms of seed glucosinolate content.

\section{REFERENCES}

Bocianowski J., Liersch A., Bartkowiak-Broda I. (2009): Investigation of phenotypic distance of F1 CMS ogura winter oilseed rape hybrids and parental lines using multivariable statistical methods. Rośliny Oleiste - Oilseed Crops XXX(2): 161-184. (in Polish).

Bocianowski J., Kozak M., Liersch A., Bartkowiak-Broda I. (2011): A heuristic method of searching for interesting markers in terms of quantitative traits. Euphytica 181: $89-100$.

Bouchereau A., Clossais-Besnard N., Bensaoud A., Leport L., Renard M. (1996): Water stress effects on rapeseed quality. European Journal of Agronomy 5: 19-30.

Brown A.F., Yousef G.G., Jeffery E.H., Klein B.P., Wallig, M.A., Kushad M.M., Juvik J.A. (2002): Glucosinolate profiles in broccoli: variation in level and implications in breeding for cancer chemoprotection. Journal of the American Society for Horticultural Science 127(5): 807-813.

Chen B., Xu K., Li X., Gao G., Yan G., Qiao J., Wu X. (2017): Evaluation of quality traits and their genetic variation in global collections of Brassica napus L. Plant Genetic Resources 16(2): 146-155.

Clossais-Besnard N. (1991): Aspects analytique et physiologiques de l'accumulation des glucosinolates chez le Colza (Brassica napus L.). Thèse of Université de Rennes 110.

Downey R.K., Bell J.M. (1990): New developments in canola research. In: Shabidi F. (ed.) Canola and rapeseed-production, chemistry, nutrition and processing technology. Van Nostrand Reinhold, New York: 37-46.

Farnham M.W., Wilson P.E., Stephenson K.K., Fahey J.W. (2004): Genetic and environmental effects on glucosinolate content and chemoprotective potency of broccoli. Plant Breeding 123: 60-65.

Friedt W., Snowdon R.J. (2009): Oilseed rape. In: Vollmann J., Rajcan I. (eds.) Handbook of plant breeding. Oil crops, vol. 4. Springer, New York: 91-126.

Gauch H.G., Zobel R.W. (1990): Imputing missing yield trial data. Theoretical and Applied Genetics 79: 753-761.

Howell P.M., Sharpe A.G., Lydiate D.J. (2003): Homoeologous loci control the accumulation of seed glucosinolates in oilseed rape (Brassica napus). Genome 46: 454-460.

Iniguez-Luy F.L., Federico M.L. (2011): The genetics of Brassica napus. In: Schmidt R., Bancroft I. (eds.) Genetics and Genomics of the Brassicaceae, Plant Genetics and Genomics: Crops and Models 9. Springer Science+Business Media, LLC 2011. DOI 10.1007/978-1-4419-7118-0_10: 291-322.

Jensen C.R., Mogensen V.O., Mortensen G., Fieldsend J.K., Milford G.F.J., Andersen M.N., Thage J.H. (1996): Seed glucosinolate, oil and protein contents on field-grown rape (Brassica napus L.) affected by soil drying and evaporative demand. Field Crops Research 47: 93-105. 
Liersch A., Bocianowski J., Bartkowiak-Broda I. (2013): Fatty acid and glucosinolate level in seeds of different types of winter oilseed rape cultivars (Brassica napus L.). Communications in Biometry and Crop Science 8(2): 39-47.

Mailer R.J., Cornish P.S. (1987): Effects of waterstress on glucosinolate and oil concentration in the seeds of rape (Brassica napus L.) and turnip (Brassica rapa L. var. silvestris (Lam) Briggs). Australian Journal of Experimental Agriculture 27: 207211.

Mithen R.F., Dekker M., Verkerk R., Rabot S., Johnson I.T. (2000): The nutritional significance, biosynthesis and bioavailability of glucosinolates in human foods. Journal of the Science of Food and Agriculture 80: 967-984.

Nowosad K., Liersch A., Popławska W., Bocianowski J. (2016): Genotype by environment interaction for seed yield in rapeseed (Brassica napus L.) using additive main effects and multiplicative interaction model. Euphytica 208: 187-194.

Nowosad K., Liersch A., Popławska W., Bocianowski J. (2017): Genotype by environment interaction for oil content in winter oilseed rape (Brassica napus L.) using additive main effects and multiplicative interaction model. Indian Journal of Genetics and Plant Breeding 77(2): 293-297.

PN ISO 9167-1:1999 (1999): Seeds of oilseed rape. Determination of the glucosinolate content. Method using high performance liquid chromatography.

Popławska W., Bartkowiak-Broda I., Liersch A., Fürguth A. (2001): Evaluation of qualitative traits of restorer lines for CMS ogura and its usefulness for the development of F1 restored hybrids of winter oilseed rape (Brassica napus L.). Rośliny Oleiste - Oilseed Crops XXII (2): 335-348 (in Polish).

Popławska W., Bartkowiak-Broda I, Szala L. (2007): Genetic and breeding evaluation of doubled haploid lines with restorer gene for CMS ogura system of winter oilseed rape (Brassica napus L.). Brassica 9(1-4): 29-32.

Purchase J.L., Hatting H., van Deventer C.S. (2000): Genotype $\times$ environment interaction of winter wheat (Triticum aestivum L.) in South Africa: II. Stability analysis of yield performance. South African Journal of Plant and Soil 17: 101-107.

Rask L., Andréasson E., Ekborm B., Eriksson S., Pontopiddan B., Meijer J. (2000): Myrosinase: gene family evolution and herbivory defense in Brassicaceae. Plant Molecular Biology 42: 93-113.

Szydłowska-Czerniak A., Bartkowiak-Broda I., Karlović I., Karlovits G., Szłyk E. (2011): Antooxidant capacity, total phenolics, glucosinolates and colour parameters of rapeseed cultivars. Food Chemistry 127: 556-563.

Thies W. (1994): Die wertbestimmenden Komponenten des Rapsschrotes. Vortr Pflanzenzüchtg 30: 89-97.

Uzunowa M., Ecke W., Weissleder K., Röbbelen G. (1995): Mapping the genome of rapeseed (Brassica napus L.) I. Construction of an RFLP linkage map and localization of QTLs for seed glucosinolate content. Theor Appl Genet 90(2): 194-204.

Walker K.C., Booth E.J. (2001): Agricultural aspects of rape and other Brassica products. Eur J Lipid Sci Technol 103: 441-446.

Wielebski F. (2006): Sulphur fertilization of different types of winter oilseed rape varieties in various soil conditions. II. Effects on quality and chemical composition of seeds. Rośliny Oleiste - Oilseed Crops XXVII(2): 283-297. 
Wittkop B., Snowdon R.J., Friedt W. (2009): Status and perspectives of breeding for enhanced yield and quality of oilseed crops for Europe. Euphytica 170: 131-140.

Zhao J., Meng J. (2003): Detection of loci controlling seed glucosinolates content and their association with Sclerotinia resistance in Brassica napus. Plant Breeding 122, 19-23.

Zobel R.W, Wright M.J., Gauch H.G. (1988): Statistical analysis of a yield trial. Agronomy Journal 80: 388-393. 